\title{
Erratum to: Ellipse-based principal component analysis for self-intersecting curve reconstruction from noisy point sets
}

\author{
O. Ruiz • C. Vanegas - C. Cadavid
}

Published online: 22 October 2010

(c) Springer-Verlag 2010

\section{Erratum to: Vis Comput}

DOI 10.1007/s00371-010-0527-x

The original version of this article unfortunately contained a mistake. The authors' affiliations have accidentally been mixed up.

The correct affiliations are given below.

The online version of the original article can be found under doi:10.1007/s00371-010-0527-x.

O. Ruiz · C. Cadavid Laboratory of CAD CAM CAE, EAFIT University, Cra 49

7-sur-50, Medellin, Colombia

O. Ruiz

e-mail: oruiz@eafit.edu.co

C. Cadavid

e-mail: ccadavid@eafit.edu.co

C. Vanegas $(\bowtie)$

Department of Computer Science, Purdue University, West Lafayette, IN 47907-2066, USA

e-mail: cvanegas@cs.purdue.edu 